\title{
Ensino de Robótica para a Promoção da Inclusão Sociodigital de Pessoas com Deficiência: um Relato de Experiência
}

\author{
Júlio César da C. Lopes1, Dilva da S. Queirós1, Hakkinen D. Santos1, Ellen \\ Souza1, Hidelberg O. Albuquerque1, Héldon José O. Albuquerque1, \\ 1Universidade Federal Rural de Pernambuco, Unidade Acadêmica de Serra Talhada - \\ PE (UFRPE-UAST), Curso de Bacharelado em Sistemas de Informação.

 \\ Abstract. This paper is about an experience report on the teaching of \\ robotics for people with intellectual and multiple disabilities who \\ participate in classes of Specialized Educational Assistance in the \\ Association of Parents and Friends of the Exceptional of Serra Talhada. The \\ objective of this study is to present a multidisciplinary method for these \\ classes, as well as to report contents taught and the resources used during \\ the lessons. The results obtained were presented with positive contributions. \\ Finally, the discussion is also presented in which the results are promising \\ for the area of inclusive Educational Robotics.
}

Resumo. Este artigo trata-se de um relato de experiência no ensino da robótica para Pessoas com Deficiência (PcD) intelectual e múltipla que participam de turmas do Atendimento Educacional Especializado (AEE) na Associação de Pais e Amigos dos Excepcionais (APAE) na cidade de Serra Talhada. O objetivo deste trabalho é apresentar um método multidisciplinar realizado para estas aulas, assim como relatar conteúdos ministrados e os recursos utilizados no decorrer das aulas. Os resultados obtidos foram apresentados de forma parcial trazendo contribuições positivas. Por fim, também está disposta neste artigo a discussão na qual os resultados são promissores para a área de Robótica Educacional (RE) inclusiva.

\section{Introdução}

As Tecnologias da Informação e Comunicação (TIC) no ambiente educacional apresentam inúmeras possibilidades na busca por um método de ensino cada vez mais lúdico e instigante (Alves, Sampaio e Elia, 2018). Segundo Morais II et al. (2018), a robótica está mudando a forma de trabalho em todo o mundo, tornando-se essencial adquirir conhecimento desta área no processo de inclusão digital.

Para Souza, Sampaio e Andrade (2018), quando se utiliza de mecanismos como a Robótica Educacional (RE) ou Robótica Pedagógica (RP), é possível desenvolver competências como o trabalho em equipe, o raciocínio lógico e a criatividade de forma mais lúdica e divertida. 
Tendo em vista as vantagens apresentadas da RE e sua importância no processo de inclusão digital, este trabalho tem como objetivo apresentar um relato de experiência com o ensino de robótica de forma multidisciplinar para PcD intelectual e múltipla atendidas pela APAE de Serra Talhada (APAE/ST), almejando o desenvolvimento sociodigital e do pensamento computacional desse público.

Assim, este trabalho está organizado da seguinte forma: a Seção 2 apresenta os trabalhos encontrados na literatura que estão relacionados com esta pesquisa; na Seção 3 , encontram-se os materiais e métodos adotados, a Seção 4 relata os resultados e, por fim, a Seção 5 apresenta a conclusão.

\section{Trabalhos Relacionados}

Nesta Seção são apresentados os trabalhos encontrados na literatura, através de busca manual nos anais do Congresso sobre Tecnologias na Educação (CTRL + E), Revista Brasileira de Informática na Educação (RBIE), Congresso Brasileiro de Informática na Educação (CBIE), Revista Tecnologias na Educação, Simpósio Brasileiro de Informática na Educação (SBIE), Workshop sobre Educação em Computação (WEI), e buscas automáticas no Portal de Periódicos CAPES e Google Scholar, no período de 2015 a 2019. Foram encontrados cinquenta e um trabalhos, destes, treze estão relacionados a este relato de experiência e por questão de espaço apenas dois estão detalhados.

Em Conchinha e Freitas (2015), os autores realizaram cinco sessões com três alunos com Síndrome de Asperger (SA), síndrome classificada atualmente como Transtorno do Espectro Austista (TEA), com intuito de fomentar a interação social e cooperação entre os participantes. Utilizando do KIT Lego ${ }^{\circledR}$ Mindstorms ${ }^{\circledR}$ NXT ${ }^{\circledR}$, os alunos aprenderam a montar, programar e interagir com o robô, porém, durante o processo, os alunos apresentaram dificuldades na montagem e também na programação, principalmente pela dificuldade em relação à lateralidade. Os três participantes aprenderam os conteúdos e desenvolveram as atividades propostas, sendo que um deles apresentou um pouco mais de dificuldade e era necessário repetir várias vezes as atividades. Os outros dois participantes mostraram mais desenvoltura na resolução dos desafios. Todos os alunos afirmaram que "gostaram muito" das atividades propostas. Os autores relataram que o KIT utilizado é uma ferramenta útil por fomentar a interação social e proporcionar novas aprendizagens.

Em Lopes et al. (2015), foram ministradas vinte aulas com duração de duas horas em um período de três meses, sendo duas aulas semanais, para estudantes com baixo desempenho no Exame Nacional do Ensino Médio (ENEM) e PcD. O trabalho apresenta oito escolas envolvidas, com sessenta e quatro participantes com idades entre dez e vinte anos, sendo um esquizofrênico, um com SA, um com Deficiência Intelectual (DI) e quatro surdos, que contavam com um interprete da Língua Brasileira de Sinais (LIBRAS). Participantes com idade entre dez e quatorze anos foram distribuídos no nível I e os demais (quinze a vinte anos) no nível II. O objetivo era promover a inclusão, proporcionar a interação dos envolvidos e verificar se, em um grupo heterogêneo, seria possível cada aluno desenvolver habilidades individuais de forma que contribuísse para o grupo. Apenas 27 alunos concluíram o projeto, vários motivos para a desistência foram relatados no trabalho. Durante a ministração das aulas, foi possível identificar pela equipe, formada por estudantes de engenharia elétrica e psicologia, o desenvolvimento de características importantes, como 
criatividade, responsabilidade, trabalho em equipe, falar em público, entre outras. O trabalho em conjunto das duas áreas (engenharia e psicologia) facilitou a identificação de falhas com relação à didática e também foi possível observar o desenvolvimento de todos os envolvidos.

O Quadro 1 traz uma análise comparativa do trabalho proposto com os trabalhos relacionados que foram aqui citados. É possível identificar um diferencial deste trabalho em relação aos demais, já que as aulas são ministradas apenas para PcD intelectual e múltipla, com um público bem maior do que os apresentados, utilizando um KIT diferente dos demais e apropriado para o público.

\section{Quadro 1. Análise comparativa}

\begin{tabular}{|c|c|c|c|}
\hline & $\begin{array}{l}\text { Conchinha e } \\
\text { Freitas } \\
\text { (2015) }\end{array}$ & Lopes et al. (2015) & Este trabalho \\
\hline $\begin{array}{l}\text { Público } \\
\text { alvo }\end{array}$ & $\begin{array}{l}\text { Pessoas com } \\
\text { Síndrome de } \\
\text { Asperger (TEA) }\end{array}$ & $\begin{array}{l}\text { Alunos do ensino fundamental e } \\
\text { médio com baixo desempenho no } \\
\text { ENEM e PcD. }\end{array}$ & PcD intelectual e múltipla. \\
\hline Recursos & $\begin{array}{l}\text { Lego } \\
\text { Mindstorms } \\
\text { NXT }\end{array}$ & $\begin{array}{l}\text { KIT Didático da Modelix*, protoboards, } \\
\text { baterias, LEDs, botoeiras, resistores, fios } \\
\text { para conexão, microprocessador } \\
\text { Arduino® UNO, sensores }(L D R, L M 35, \\
\text { infravermelho, Reed Switch), robô } \\
\text { UAIrobotsLine, lanternas, KIT Didático } \\
\text { da Lego*, componentes eletrônicos de } \\
\text { baixo custo, materiais descartados. }\end{array}$ & $\begin{array}{l}\text { KIT Lego Boost }(\text {, tablets e } \\
\text { Computação desplugada. }\end{array}$ \\
\hline $\begin{array}{l}\text { Alunos } \\
\text { por } \\
\text { turma }\end{array}$ & 3 alunos & 4 turmas de 16 participantes cada. & $\begin{array}{l}6 \text { turmas com média de } 20 \\
\text { alunos cada. }\end{array}$ \\
\hline $\begin{array}{l}\text { Carga } \\
\text { horária } \\
\text { Frequência/ } \\
\mathrm{N}^{0} \text { de Aulas }\end{array}$ & 5 sessões & $\begin{array}{l}20 \text { aulas com duração de } 2 \text { horas } \\
\text { cada, ministradas duas vezes por } \\
\text { semana durantes três meses. }\end{array}$ & $\begin{array}{l}\text { - } 1 \text { hora/aula semanal, sendo } \\
\text { utilizado o KIT de Robótica } \\
\text { uma vez por mês; } \\
\text { - As aulas ocorrem durante } \\
\text { todo o ano. }\end{array}$ \\
\hline $\begin{array}{l}\text { Conteúdos } \\
\text { abordados }\end{array}$ & $\begin{array}{l}\text { Construção e } \\
\text { programação } \\
\text { do robô e } \\
\text { interação dos } \\
\text { participantes. }\end{array}$ & $\begin{array}{l}\text { Montagem mecânica, Eletrônica e } \\
\text { Programação. }\end{array}$ & $\begin{array}{l}\text { Informado na metodologia } \\
\text { deste trabalho. }\end{array}$ \\
\hline
\end{tabular}

Fonte: Elaborado pelos Autores (2019)

\section{Materiais e Métodos}

Na Seção 3.1, é apresentada a equipe, assim como a sua divisão na realização de tarefas do projeto. Já na Seção 3.2, é apresentado o público alvo que este projeto abrange e como estão dispostas as turmas que participam das aulas. Na Seção 3.3, é apresentado o KIT que é utilizado na didática das aulas e todos os recursos que o compõe. Por fim, na Seção 3.4, são apresentadas as etapas de construção da aula, assim como o método adotado para as aulas e os conteúdos a serem ministrados.

\subsection{Equipe}

Este projeto iniciou-se em 2018 e continua em andamento desde fevereiro do ano de 2019. Com uma nova equipe formada por sete discentes do curso de Bacharelado em 
Sistemas de Informação (BSI) e extensionistas do Projeto de Extensão Inclusão Digital vinculado a Universidade Federal Rural de Pernambuco - Unidade Acadêmica de Serra Talhada (UFRPE/UAST), sendo as aulas de robótica ministradas por três dos extensionistas deste projeto. Dois são responsáveis pela aula e o outro é responsável por analisar e documentar o desempenho dos usuários utilizando um formulário elaborado pelos extensionistas e que foi validado pela coordenadora do projeto de extensão e pela equipe pedagógica da UFRPE/UAST. Além disso, os extensionistas participaram de oficinas formativas com a equipe pedagógica, já que todos são estudantes de bacharelado, curso sem foco na formação de educadores, como é no caso das licenciaturas.

\subsection{Público alvo}

A APAE/ST tem como missão contribuir para autonomia e qualidade de vida de trezentos e setenta PcDI, através de uma equipe interdisciplinar com a participação de pais e amigos. Desses usuários, cento e vinte participam das aulas de Letramento Digital e são divididos em seis turmas do Atendimento Educacional Especializado (AEE) de diferentes faixas etárias. São elas:

- AEE II A (manhã) e B (tarde) - 11 a 17 anos.

- AEE III A (manhã) e B (tarde) - 18 a 30 anos.

- AEE IV A (manhã) e B (tarde) - 31 a 60 anos.

Para que de fato as aulas pudessem ser ministradas com participação de todos, fez-se necessário realizar primeiro um estudo para verificar quais as deficiências que cada usuário possui para que fosse possível ofertar uma aula que realmente incluísse todos os participantes do projeto. Verificou-se que o público é muito heterogêneo, além da DI, existem usuários no grupo com Autismo, Epilepsia, Hidrocefalia, Síndrome de Down e Paralisia Cerebral, juntamente com deficiência física.

\subsection{KIT de Robótica}

O KIT de robótica escolhido para as aulas é o KIT Lego Boost ${ }^{\circledR}$, o qual possui 847 peças de montagem, incluindo um move hub, peça principal do KIT que utiliza seis pilhas AAA, um sensor de cor e distância e um motor interativo. Com o KIT é possível montar diversos tipos de robôs, porém, a própria LEGO disponibiliza manuais com detalhes para construção de cinco robôs, sendo eles: o Vernie, Frankie, Guitar 4000, M.I.R. 4 e Auto Builder. O KIT também oferece um software que permite uma programação visual e está disponível nas seguintes plataformas: Apple iOS, Microsoft Windows e Google Android. Dessa forma, este KIT foi escolhido por oferecer várias opções de montagens e por ser composto por muitas peças, sendo elas em sua maioria pequenas, tendo em vista que muitos dos usuários da APAE/ST possuem uma motricidade fina comprometida.

\subsection{Organização das Aulas}

\subsubsection{Processo de Construção das aulas}

O processo de construção das aulas segue um padrão composto por quatro etapas. Planejamento da aula: nesta etapa, é definido o conteúdo que será ministrado na aula, a parte do robô que será construída pelos usuários, como também a sequência dos assuntos que será apresentada à turma e a maneira como serão dispostas as etapas de build, code e play. Preparação da aula: nessa etapa, são elaborados os recursos que 
serão necessários para as aulas como pistas, montagem de uma parte do robô, adaptações necessárias para atividades. Validação: a aula é avaliada pela equipe pedagógica e pela coordenadora do projeto de extensão, nessa etapa também é sugerido o que é possível melhorar, é verificado se a aula inclui todos os usuários, é necessária essa verificação devido a grande heterogeneidade das turmas. Também, é discutido a respeito dos pontos positivos e negativos das aulas anteriores. E por fim, a ministração da aula.

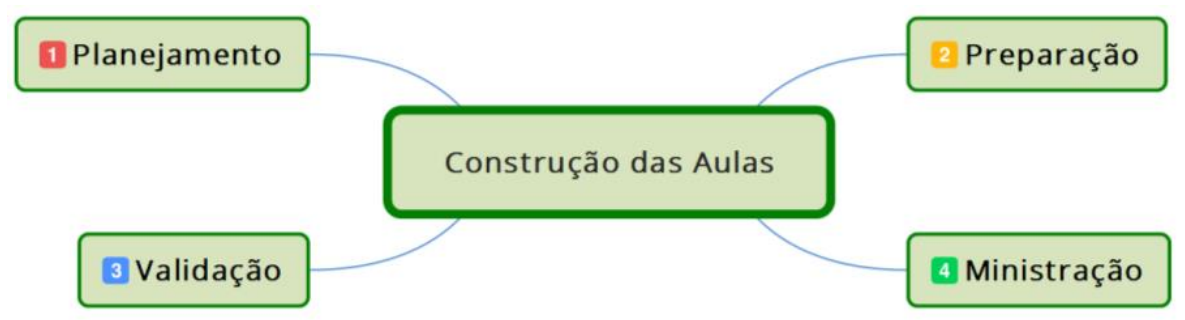

Figura 1. Método adotado para Construção das Aulas Fonte: Elaborada pelos Autores (2019)

\subsubsection{Build, Code e Play}

A primeira etapa da aula, que é a construção do robô (BUILD) além de exercitar a coordenação motora, também ajuda na capacidade de abstração e imaginação, pois para essa etapa os usuários precisam analisar as sequências e regras do manual para conseguir construir as partes faltantes do robô. Na segunda etapa (CODE), faz-se necessário o reconhecimento dos blocos de comando assim como o uso da lógica e sequências de ações para que o robô execute-as. Por fim, a etapa (PLAY) consiste em montar e executar os comandos da etapa anterior nos tablets e analisar se o robô executou de maneira correta os problemas apresentados em sala de aula. A programação é rápida e fácil, já que não é necessário escrever linhas de código, utilizase apenas o método arrastar e soltar (drag and drop) blocos de forma sequencial, permitindo que usuários não alfabetizados participem das aulas sem prejuízos.
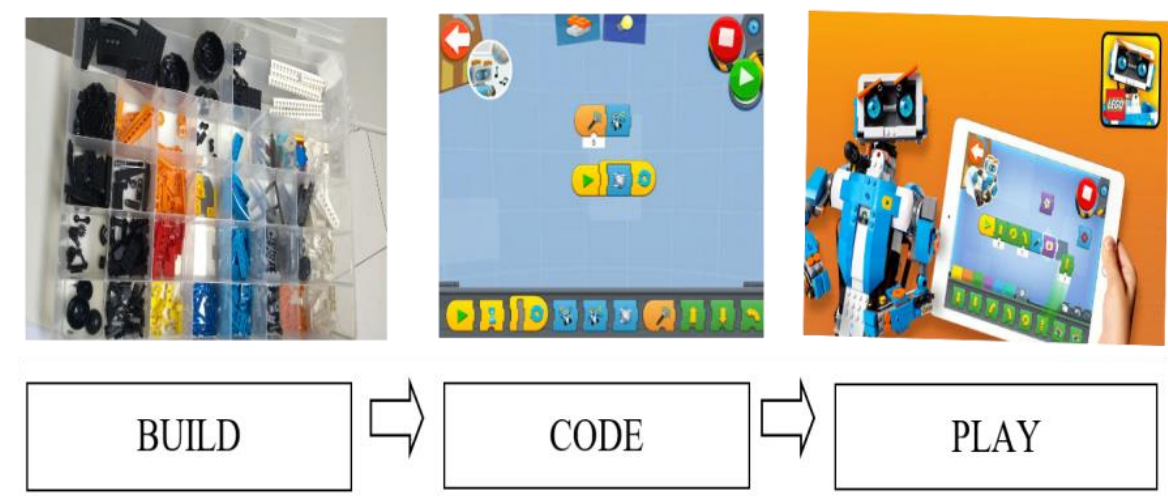

Figura 2. Método proposto pelo KIT Lego Boost e adotado neste trabalho Fonte: Adaptada de The LEGO Boost

\subsubsection{Conteúdo Planejado}

Além do desenvolvimento do pensamento computacional, a RE proporciona a multidisciplinaridade, já que pode ser utilizada para abordar diversos conteúdos e até mesmo melhorar as relações sociais e promover a inclusão (Morais II et al. (2018)). 
Além do KIT Lego Boost ${ }^{\circledR}$, utilizamos recursos que facilitam a compreensão dos assuntos abordados e que tornam as aulas mais atrativas, como por exemplo, a computação desplugada (Bell et al. (2011)), método utilizado para o ensino do pensamento computacional sem o uso de recursos digitais, e também a utilização de pistas para movimentação do robô confeccionada pelos próprios extensionistas, com sua utilização foi constatado que é um bom método, levando em consideração que as PcD intelectual têm uma pequena capacidade de abstração, dificultando a imaginação de um cenário para resolução dos desafios propostos durante as aulas, sendo assim, as pistas contribuem no desenvolvimento cognitivo dos participantes.

\section{Quadro 2. Planejamento das aulas}

\begin{tabular}{|c|c|c|c|}
\hline Aulas & Temas & Atividades desenvolvidas & Materiais utilizados \\
\hline $\begin{array}{l}\text { Aula } 01- \\
\text { Aprendendo a } \\
\text { montar e } \\
\text { programar }\end{array}$ & $\begin{array}{l}\text { Montagem e } \\
\text { programação. }\end{array}$ & $\begin{array}{l}\text { Em equipe: montagem das partes faltosas do } \\
\text { M.I.R. } 4 \text { e programação para o robô se } \\
\text { movimentar na pista para os locais solicitados. }\end{array}$ & $\begin{array}{l}\text { KIT Lego Boost } \mathbb{\circledR}, \text { tablets e } \\
\text { pista para movimentação do } \\
\text { robô. }\end{array}$ \\
\hline $\begin{array}{l}\text { Aula } 02 \text { - Tudo } \\
\text { limpo }\end{array}$ & $\begin{array}{l}\text { Comandos básicos } \\
\text { de ação e higiene } \\
\text { pessoal. }\end{array}$ & $\begin{array}{l}\text { Em equipe: montagem das partes faltosas do } \\
\text { Vernie e programação para o robô se movimentar } \\
\text { na pista para coletar materiais espalhados de } \\
\text { higiene pessoal. }\end{array}$ & 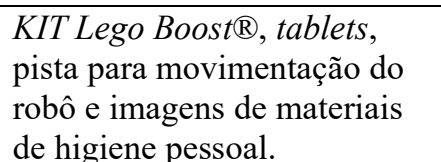 \\
\hline $\begin{array}{l}\text { Aula } 03- \\
\text { Lateralidade }\end{array}$ & $\begin{array}{l}\text { Computação } \\
\text { desplugada e } \\
\text { orientação espacial. }\end{array}$ & $\begin{array}{l}\text { Atividades práticas para aprendizagem de } \\
\text { lateralidade. }\end{array}$ & $\begin{array}{l}\text { Fitas coloridas, bambolês, } \\
\text { atividades } \\
\text { Impressas. }\end{array}$ \\
\hline $\begin{array}{l}\text { Aula } 04- \\
\text { Vendendo e } \\
\text { lucrando }\end{array}$ & $\begin{array}{l}\text { Comandos básicos } \\
\text { de ação e voz, e } \\
\text { educação } \\
\text { Financeira. }\end{array}$ & $\begin{array}{l}\text { Cada equipe recebia um valor em dinheiro fictício } \\
\text { e deveria colocar um preço nas peças do robô que } \\
\text { não iriam utilizar e comprar à outra equipe as } \\
\text { peças que faltam para concluir a montagem. }\end{array}$ & $\begin{array}{l}\text { KIT Lego Boost }{ }^{\circledR} \text {, tablets, } \\
\text { pista para movimentação do } \\
\text { robô e imagens de todas as } \\
\text { notas de dinheiro e de } \\
\text { barracas, para representar cada } \\
\text { equipe. }\end{array}$ \\
\hline $\begin{array}{l}\text { Aula } 05- \\
\text { Colorindo }\end{array}$ & $\begin{array}{l}\text { Explorando o } \\
\text { sensor de cor e } \\
\text { noção de cores }\end{array}$ & $\begin{array}{l}\text { Cada equipe deve programar o robô para } \\
\text { reconhecer as cores e executar as ações } \\
\text { determinadas pelos professores. }\end{array}$ & 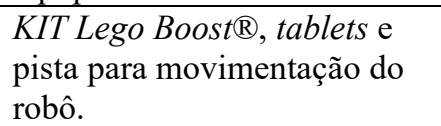 \\
\hline $\begin{array}{l}\text { Aula } 06- \\
\text { Vernie Tagarela }\end{array}$ & $\begin{array}{l}\text { Explorando o } \\
\text { sensor de cor, } \\
\text { blocos de voz e } \\
\text { sinais de trânsito. }\end{array}$ & $\begin{array}{l}\text { Cada equipe deve criar um cenário real de trânsito } \\
\text { e explorar o sensor de cor, blocos de voz para } \\
\text { resolver os desafios propostos. }\end{array}$ &  \\
\hline $\begin{array}{l}\text { Aula } 07- \\
\text { Aprendendo a } \\
\text { andar }\end{array}$ & $\begin{array}{l}\text { Montagem e } \\
\text { programação. }\end{array}$ & $\begin{array}{l}\text { Em equipe: montagem das partes faltosas do } \\
\text { M.I.R. } 4 \text { e programação para o robô se } \\
\text { movimentar na pista obedecendo às instruções dos } \\
\text { professores. }\end{array}$ &  \\
\hline Aula 08 - Coleta & $\begin{array}{l}\text { Montagem e } \\
\text { programação. }\end{array}$ & $\begin{array}{l}\text { Em equipe: montagem das partes que faltam do } \\
\text { M.I.R. } 4 \text { e programação para o robô se } \\
\text { movimentar na pista e coletar o que estiver } \\
\text { espalhado nela. }\end{array}$ & 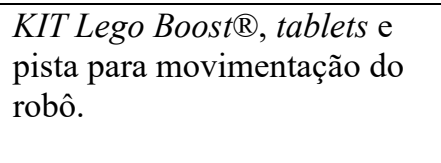 \\
\hline $\begin{array}{l}\text { Aula } 09- \\
\text { Gincana }\end{array}$ & Gincana. & $\begin{array}{l}\text { Atividades lúdicas explorando os conceitos } \\
\text { aprendidos nas aulas anteriores. }\end{array}$ &  \\
\hline $\begin{array}{l}\text { Aula } 10- \\
\text { Reciclando }\end{array}$ & Reciclagem. & Montagem de robôs com material reciclado. & Material reciclado. \\
\hline
\end{tabular}




\section{Resultados}

Os Resultados serão divididos em três Subseções, denominadas Aulas Realizadas, Entrevista e Discussões, a fim de detalhar cada uma.

\subsection{Aulas Realizadas}

Dos conteúdos apresentados no Quadro 2, foram ministradas as aulas de um a quatro. Vale ressaltar que esses conteúdos podem sofrer alterações de acordo com a necessidade de cada turma. Por questão de espaço, nesta Seção serão apresentadas com detalhes as aulas dois e três.

$\mathrm{Na}$ aula 02 foi executada a etapa BUILD. Foram montados os cones e aliens, devido ao curto tempo das aulas não é possível montar todo o robô. Foram apresentados para os usuários os primeiros blocos de programação, etapa $C O D E$, sendo eles: MOVER PARA FRENTE, MOVER PARA TRÁS, MOVER PARA A DIREITA E MOVER PARA A ESQUERDA. Para a parte prática (PLAY), utilizamos os tablets e uma pista confeccionada pelos próprios extensionistas. Os usuários divididos em equipes tinham que fazer com que o robô se movimentasse na pista para coletar materiais espalhados de higiene pessoal, de acordo com uma história.

Nesta aula foi possível identificar que os usuários apresentavam grandes dificuldades relacionadas à orientação espacial, levando eles a errar várias vezes o trajeto que o robô deveria percorrer, quando deveria ir para a esquerda girava para a direita, por exemplo. Mesmo diante desse problema, após várias tentativas e com o auxílio dos extensionistas os usuários conseguiram solucionar os desafios.


Figura 3. Registros da Aula 02

Fonte: Elaborada pelos autores (2019) 
Quando discutido com a coordenadora e equipe pedagógica a respeito da aula 02, concluiu-se que seria necessária uma aula para reforçar conceitos de orientação espacial devido à dificuldade dos usuários, tornando-se o tema da aula 03. Nesta aula, foram desenvolvidas atividades com foco no ensino da lateralidade. Quando os usuários entravam no laboratório para a aula, os extensionistas já colocavam no pulso esquerdo deles uma fita verde e no direito uma amarela. Logo, depois de explicarmos as sentidos, sendo elas: DIREITA, ESQUERDA, FRENTE e TRÁS, entregamos uma folha impressa com a imagem de um robô e mais dois lápis, um verde e um amarelo para cada usuário, para que eles pudessem associar a cor com o sentido e pintar os braços e pernas do robô com a cor correspondente a fita do pulso. Concluída essa atividade, foram distribuídos seis bambolês pelo chão da sala para que de forma individual pudessemos mais uma vez trabalhar a lateralidade. A pedido dos extensionistas, os usuários se locomoviam entres os bambolês.

Pelo fato das turmas serem bem heterogêneas, então adaptamos a dinâmica aos usuários que possuem deficiência física utilizando um tabuleiro (desenho em forma de jogo da velha), no qual os usuários teriam que mover a peça para os sentidos indicados ao invés de locomover seu corpo nos bambolês. Para finalizar esta aula, entregamos imagens impressas dos blocos para programação do robô ensinados na Aula 01 e 02, para que eles pudessem colocá-los no local correto.

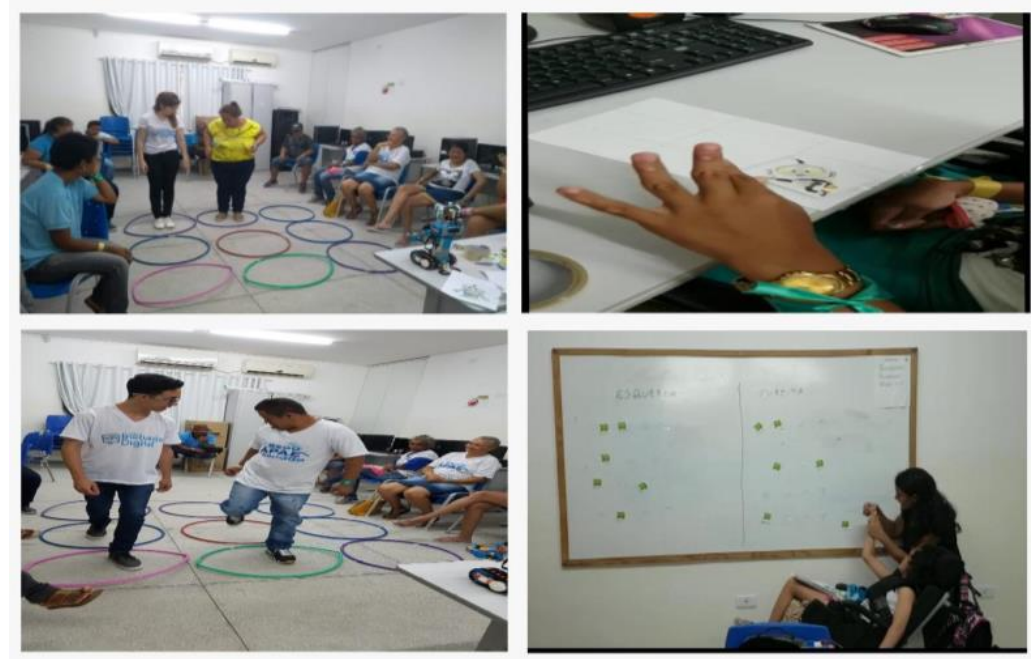

Figura 4. Registros da Aula 03

Fonte: Elaborada pelos autores (2019)

\subsection{Entrevista}

Após a ministração das quatro primeiras aulas, foi realizada uma entrevista com os usuários e professores do AEE, que também acompanham os usuários durante as aulas. Foi possível identificar alguns resultados positivos com relação ao método de ensino proposto. Ao entrevistar os usuários, 91\% afirmaram que gostam das aulas, 77\% afirmaram nunca ter contato com a robótica antes do início do projeto, mais de $80 \%$ considera que o KIT é fácil de ser montado e programado. Porém, apenas $60 \%$ diz que consegue montar com facilidade e $80 \%$ afirma conseguir programar com facilidade. Ao entrevistar os professores, $100 \%$ afirmaram que a robótica trabalhada de forma multidisciplinar é uma vantagem, que os conteúdos são adequados ao público, e que a pista de movimentação do robô é uma boa opção para as aulas; $83 \%$ consideram as 
aulas de Letramento Digital relevantes para a formação dos usuários e 66\% afirmam que é possível notar uma evolução dos participantes com relação ao pensamento computacional. Foi escolhida a entrevista ao invés de um questionário porque a grande maioria dos participantes não é alfabetizada.

\subsection{Discussão}

Ao longo das aulas, foi possível identificar uma evolução significativa por parte da maioria dos usuários na etapa BUILD, comprovando que o KIT Lego Boost $\AA$ auxilia no processo de aprimoramento da motricidade fina dos participantes. $\mathrm{Na}$ etapa $C O D E$, alguns já conseguem desenvolver a programação para resolução dos problemas propostos pelos extensionistas sem ajuda, e outros usuários ainda apresentam dificuldades, confundem a função dos blocos ou até mesmo os sentidos (frente, trás, direita e esquerda).

Durante as aulas, verificamos que um dos participantes se sobressaía diante dos demais em todas as aulas, sempre liderava seu grupo e resolvia os exercícios propostos com muita facilidade. Diante disso, na reunião de validação das aulas foi discutido sobre o seu bom desempenho e foi sugerido que ele fosse monitor nas aulas de Robótica para melhor integração dele com os alunos de todas as turmas da APAE e para adquirir experiência com o ensino. O usuário aceitou e vem apresentando um bom desempenho como monitor.

A RE auxilia no desenvolvimento de habilidades como o raciocínio lógico, a criatividade e inclusão social. Ressaltamos a grande evolução dos participantes do projeto quanto à interação social, evidenciada em todas as etapas da aula (build, code, play). Nota-se que os usuários sempre interagem com os extensionistas de forma positiva e também se ajudam mutuamente, como apresenta a Figura 3, tornando-se agentes ativos na construção do conhecimento em sala de aula.

\section{Conclusão}

O trabalho descrito relata a experiência da utilização da robótica na APAE/ST como ferramenta educacional para $\mathrm{PcD}$ intelectual e múltipla, evidenciando-se como um método bastante eficaz que contribui para o processo de inclusão sociodigital dessas pessoas de forma lúdica, criativa e multidisciplinar, além de proporcionar a participação de todos os envolvidos no processo de ensino-aprendizagem. É possível identificar que o trabalho proposto ainda está em andamento, no entanto é perceptível que todos os objetivos previamente traçados foram alcançados.

Segundo Morais II et al. (2018), o estudo da robótica é, certamente, uma ferramenta notável de motivação de jovens. É fácil encontrar aqueles que se sintam curiosos ou motivados pela área. Sendo assim, o KIT Lego Boost ${ }^{\circledR}$ torna-se uma excelente opção diante do método de ensino proposto neste trabalho pela facilidade de montagem de robôs devido ao manual intuitivo, pela facilidade no processo de programação.

Além do aprendizado e experiência que os usuários adquiriram, vale ressaltar que os extensionistas aprenderam e se desenvolveram bastante, principalmente por ser a primeira vez que estiveram exercendo o papel de professores com um público diferente da realidade vivida por cada um. Sendo necessário participar de oficinas 
formativas para saber como proceder nas aulas e com incluir todos os participantes. É necessário considerar que todos são estudantes de bacharelado, fato já supracitado. Além disso, os extensionistas se sentem felizes e realizados por contribuírem para o desenvolvimento e autonomia de cada participante.

Sendo assim, para trabalhos futuros, serão ministradas no próximo semestre, o restante das aulas já planejadas, será analisado o desempenho das turmas e verificado a necessidade de mudanças no cronograma, além do desenvolvimento de novas possibilidades para melhorar o ensino de robótica.

\section{Referências}

BELL, T.; WITTEN, I. H.; FELLOWS, M. Computer Science Unplugged. 2011.

MORAIS II, M. J. O.; DANTAS, K. A.; SENA, R. A. S.; NASCIMENTO, V. K. D. Inclusão Digital de Crianças e Adolescentes por meio da Robótica Educacional. In: Anais do III Congresso sobre Tecnologias na Educação (CTRL+E-2018).

CONCHINHA, C.; DE FREITAS, J. C. Robots \& Necessidades Educativas Especiais: a Robótica Educativa Aplicada a Alunos Autistas. In: Atas da IX Conferência Internacional de TIC na Educação, p. 21-35, maio de 2015.

LOPES, LÍDIA; DOS SANTOS, L. M. M.; DE SOUZA, L. F. F.; BARROSO, M. F. S.; DA SILVA, C. V.; SERPA, B. R.; PEREIRA, E. B.. A Robótica Educacional Como Ferramenta Multidisciplinar: Um Estudo de Caso Para a Formação e Inclusão de Pessoas com Deficiência. In: Revista Educação Especial, v. 28, n. 53, p. 735-750, set./dez. 2015.

SOUZA, I. M. L.; SAMPAIO, L. M. R.; ANDRADE, W. L. Explorando o Uso da Robotica na Educação Básica: um estudo sobre ações práticas que estimulam o Pensamento Computacional. In: Anais dos Workshops do VII Congresso Brasileiro de Informática na Educação (WCBIE 2018). 